\title{
Comparison of the effects of high- and low-methoxyl pectins on blood and faecal lipids in man
}

\author{
By PATRICIA A. JUDD AND A. S. TRUSWELL* \\ Department of Food Science and Nutrition, Queen Elizabeth College, Campden Hill Road, \\ London W8 7 AH
}

(Received 27 January 1982-Accepted 24 March 1982)

\begin{abstract}
1. The effects on blood and faecal lipids of the addition of $15 \mathrm{~g}$ of either high- or low-methoxyl pectin to the habitual diets of ten healthy young adults have been studied.

2. Serum total cholesterol levels were reduced by a mean of $16 \%$ during consumption of low-methoxyl pectin and $18 \%$ during consumption of high-methoxyl pectin. High density lipoprotein cholesterol levels and triglyceride levels were unchanged.

3. There was no difference in faecal fat and steroid excretion between the two pectins.

4. The results suggest that it is the gel-forming properties of the pectins which are important in the cholesterol-lowering effect rather than differences in bile acid binding due to different methoxyl contents.
\end{abstract}

Pectins are polygalacturonic acid polymers, occurring naturally in plant cell-walls, and are part of the dietary fibre complex. The carboxyl groups of the constituent galacturonic acid molecules are esterified to varying extents, usually with methanol (Rees, 1967) and pectins can be described as high- or low-methoxyl (HMP and LMP respectively), the latter having less than $50 \%$ of possible carboxyl groups esterified (Kertesz, 1963).

The plasma cholesterol-lowering effects of pectin in man have been investigated in at least eleven studies, summarized by Kay et al. (1978). In all but the studies of Delbarre et al. (1977) and Fahrenbach et al. (1965), where daily doses of polymer were low $(6 \mathrm{~g} / \mathrm{d}$ in each instance), pectin has been shown to reduce plasma cholesterol levels.

The type of pectin used in most experiments has been described as 'Pectin NF' a relatively high-methoxyl product with $65-75 \%$ of possible carboxyl groups esterified (American National Formulary XIII, 1970). The exception was the work of Delbarre et al. '1977) where neither lemon pectin (approximately 40\% esterified) nor apple pectin (degree of methoxylation $70 \%$ ) was effective at a dose of $6 \mathrm{~g} / \mathrm{d}$.

Studies in rats have suggested that only pectins with a high-methoxyl content are effective plasma cholesterol-lowering agents (Ershoff \& Wells, 1962; Mokady, 1973). However, we have demonstrated a significant cholesterol-lowering effect for LMP in animal studies (Judd et al. 1977). In the study by Ershoff \& Wells (1962) cholesterol levels of rats given $50 \mathrm{~g} \mathrm{LMP} / \mathrm{kg}$ were lower than controls, although this did not reach statistical significance. Similarly, in the study by Mokady (1973), there was no difference between the cholesterol levels of rats given pectins with approximately 26 and $49 \%$ of possible carboxyl groups esterified. The only significant reduction was achieved with a pectin of $51 \%$ esterification.

Durrington et al. (1976) and Kay \& Truswell (1977) have also suggested that the methoxyl content of pectins may determine, in part, their effectiveness as cholesterol-lowering agents, but the latter workers also suggested that the viscosity of pectin and the form in which it is fed are more important.

The present experiment was therefore designed to compare the effect of HMP and LMP on blood and faecal lipids in healthy adults, in order to assess the usefulness of LMP as

\footnotetext{
- Present address: Biochemistry Department, University of Sydney, N.S.W. 2006, Australia.
} 
Table 1. Chemistry of high-and low-methoxyl pectins

\begin{tabular}{lccc}
\hline & $\begin{array}{c}\text { Degree of } \\
\text { methoxylation* }(\%)\end{array}$ & $\begin{array}{c}\text { Anhydrous uronic } \\
\text { acid (\%) }\end{array}$ & Inherent viscosity $\dagger$ \\
\hline High-methoxyl (PB101) & $70 \cdot 7$ & 82.9 & 4.43 \\
Low-methoxyl (PB611) & 37.2 & $82 \cdot 1$ & 3.26 \\
\hline
\end{tabular}

* Percentage of uronic acids with methyl groups.

$\dagger$ Inherent viscosity $=\frac{\text { specific viscosity }^{-1}}{\text { concentration }}=100 \mathrm{ml} / \mathrm{g}$ (McKay et al. 1969).

$\ddagger$ Pectins supplied and analysed by H. P. Bulmer Ltd, Hereford. Pectins were citrus pectins; the low-methoxyl type was prepared from a high-methoxyl type by maintaining at $\mathrm{pH} 1-1.5$ and $40^{\circ}$ for several days.

a hypocholesterolaemic agent and to obtain further insight into the mechanism of action of viscous polysaccharides.

\section{METHODS}

Subjects and dietary intakes

Ten postgraduate students, or members of staff of this department, five male and five female, took part in the study and all had experience in recording dietary intakes. Ages ranged from 23 to 38 years and all were apparently healthy and within $15 \%$ of ideal body-weight.

The study lasted 7 weeks during which the subjects continued to eat their habitual diets; $15 \mathrm{~g}$ pectin being taken in addition during weeks $2-7$. They were asked to record all food and drink eaten during the study, in booklets provided. During weeks 1,4 and 7 all food was weighed and the weight recorded (using Salter dietary balances) as well as a description of the portion in 'household' measures. During the intervening 4 weeks household measures only were used. During weeks 5-7 the subjects' record books for the previous 3 weeks were returned to them and they were asked to consume similar meals during the second 3-week period. Nutrient intakes for the whole period were analysed using a computer program based on current food tables (Paul \& Southgate, 1978).

After the first week, subjects were randomly assigned to one of two groups and the two types of pectin added to their diets in a crossover design. Group A consumed $15 \mathrm{~g} \mathrm{HMP}$ during weeks $2-4$ followed by $15 \mathrm{~g}$ LMP during weeks $5-7$. Group B took the pectins in reverse order.

Two citrus pectins (supplied by H. P. Bulmer Ltd, Hereford) were used, the HMP having a methoxyl content of $71 \%$ and the LMP $37 \%$. (Further chemical and physical properties are shown in Table 1).

The pectins were incorporated into a jelly, the daily portion of which contained $15 \mathrm{~g}$ pectin, $50 \mathrm{~g}$ 'Ribena' blackcurrant juice, $20 \mathrm{~g}$ sucrose and $150 \mathrm{ml}$ water. Subjects consumed the jelly in divided doses at, and in addition to, their main meals.

Volunteers were weighed weekly and kept a record of exercise, bowel habit, gastrointestinal problems and other relevant information in the food-record books.

Fasting blood samples $(6 \mathrm{ml})$ were taken on the last three mornings of each week after the subjects had rested for $20 \mathrm{~min}$ to stabilize blood volume (Tan et al. 1973). Serum was separated and stored at $-22^{\circ}$ for analysis of total cholesterol and triglycerides. High-density lipoprotein (HDL) was separated by precipitation with heparin and manganese chloride (Carlson, 1973) and stored frozen for subsequent cholesterol analysis. Cholesterol was determined by an enzymic method (Trinder, 1969) and triglycerides were estimated enzymically after saponification with ethanolic potassium hydroxide (Eggstein, 1966). 
Table 2. Daily nutrient intakes of healthy human volunteers

(Mean values with their standard errors)

\begin{tabular}{|c|c|c|c|c|c|c|c|c|c|c|c|c|c|c|}
\hline \multirow{2}{*}{$\begin{array}{l}\text { Week } \\
\text { of } \\
\text { study }\end{array}$} & \multicolumn{2}{|c|}{$\begin{array}{l}\text { Protein } \\
\text { (g) }\end{array}$} & \multicolumn{2}{|c|}{$\begin{array}{c}\text { Fat } \\
\text { (g) }\end{array}$} & \multicolumn{2}{|c|}{$\begin{array}{l}\text { Carbohydrate } \\
\text { (g) }\end{array}$} & \multicolumn{2}{|c|}{$\begin{array}{l}\text { Energy } \\
(\mathrm{g})\end{array}$} & \multicolumn{2}{|c|}{$\begin{array}{l}\text { Dietary fibre } \\
(\mathrm{g})\end{array}$} & \multicolumn{2}{|c|}{$\begin{array}{l}\text { Cholesterol } \\
\text { (g) }\end{array}$} & \multicolumn{2}{|c|}{$\begin{array}{l}\text { Alcohol } \\
\text { (g) }\end{array}$} \\
\hline & Mean & SE & Mean & SE & Mean & $\mathbf{S E}$ & Mean & $\mathbf{S E}$ & Mean & $\mathbf{S E}$ & Mean & $\mathbf{S E}$ & Mean & $\mathbf{S E}$ \\
\hline 1 & 7 & 4 & 101 & 9 & 247 & 24 & 9.7 & 0. & 22 & 2 & 28 & 24 & 27 & 10 \\
\hline 2 & 77 & 4 & 105 & $\cdot 6$ & 2 & 30 & $10 \cdot 1$ & 0 & 21 & 2 & 32 & 34 & 34 & 11 \\
\hline 3 & 7 & 4 & 88 & 10 & 2 & 22 & 9.9 & 0 & 1 & 1 & & 26 & 29 & 8 \\
\hline 4 & 82 & 6 & 116 & 12 & 2 & 23 & 10.9 & 0 & 23 & 2 & 300 & 23 & 42 & 12 \\
\hline 5 & 80 & 6 & 107 & 11 & 25 & 25 & $10 \cdot 0$ & 0 & 22 & 2 & 2 & 27 & 35 & 11 \\
\hline 6 & 72 & 7 & 98 & 13 & 240 & 26 & 9. & 0. & 20 & 2 & 290 & 39 & 29 & 10 \\
\hline 7 & 76 & 6 & 106 & 10 & 244 & 23 & $10 \cdot 2$ & 0.9 & 20 & 2 & 302 & 26 & 34 & 11 \\
\hline
\end{tabular}

Analysis of variance showed no difference between weeks 1-7 for any nutrient.

During weeks 4 and 7, $5 \mathrm{~d}$ faecal collections were made using carmine BPC ( $500 \mathrm{mg}$ in gelatin capsules) to mark the beginning and end of collection and chromium sesquioxide $(1.5 \mathrm{~g} / \mathrm{d}$, providing $1.025 \mathrm{~g}$ chromium, in divided doses) as an internal marker (Rose, 1964). Chromium sesquioxide was taken for $5 \mathrm{~d}$ before commencing each collection in order to allow equilibration with gut contents. Transit time was taken as time from consumption of the carmine marker to its appearance in the faeces.

Faeces were collected in plastic bags and frozen immediately. Each individual's collection was pooled, weighed and homogenized in a Colworth Stomacher 3000. Portions were taken for analysis of chromium by the method of Whitby \& Lang (1960). Duplicate $50 \mathrm{~g}$ portions were taken, freeze-dried to constant weight and ground to a fine powder for analysis of faecal lipids.

Total faecal fat was determined gravimetrically after refluxing for $24 \mathrm{~h}$ in boiling light petroleum (b.p. $60-80^{\circ}$ ). Faecal bile acids and neutral steroids were determined by the method of Evrard \& Janssen (1968) as modified by Mitchell $e$ t al. (1973). All faecal variables were corrected to $\mathrm{Cr}$ output. Statistical analysis was done by Students's paired $t$-test. The experiment was approved by the Human Experimentation Committee of Queen Elizabeth College.

\section{RESULTS}

\section{General}

Week-to-week variations in weight were minimal for all subjects and showed no long-term trend. Mean weights $( \pm \mathrm{SD})$ at the end of the $1 \mathrm{st}, 4 \mathrm{th}$ and 7 th weeks were $(\mathrm{kg}): 70 \cdot 2 \pm 9 \cdot 7$, $70 \cdot 6 \pm 9.7$ and $70 \cdot 6 \pm 9 \cdot 8$ respectively.

Nutrient intake varied, as shown in Table 2. The mean intakes of all subjects over the 7-week period did not differ greatly from week to week. Analysis of variance of the results for each nutrient showed no significant differences between each subject's intakes over the 7 weeks, or in the mean nutrient intakes for all subjects. Paired $t$-tests comparing mean nutrient intakes during the high-methoxyl period with the low-methoxyl period also showed no significant difference. Similarly, no differences were found between nutrient intakes in the baseline week and the first week in which pectin was consumed.

The greatest change in the diet was therefore the addition of $15 \mathrm{~g}$ pectin and $50 \mathrm{~g}$ carbohydrate in the jelly, the latter providing an extra $0.7 \mathrm{MJ} / \mathrm{d}$. These changes represented 
Table 3. Summary of serum lipid concentrations (mol/l) of healthy adult human volunteers given low- and high-methoxyl pectins

(Mean values with their standard errors for ten subjects for cholesterol and nine subjects for triglycerides)

\begin{tabular}{|c|c|c|c|c|c|c|}
\hline & \multirow{2}{*}{\multicolumn{2}{|c|}{$\begin{array}{l}\text { At the end of } \\
\text { baseline week }\end{array}$}} & \multicolumn{4}{|c|}{ After three weeks on each pectin } \\
\hline & & & \multicolumn{2}{|c|}{ High-methoxyl } & \multicolumn{2}{|c|}{ Low-methoxyl } \\
\hline & Mean & SE & Mean & $\mathrm{SE}$ & Mean & $\mathbf{S E}$ \\
\hline Total cholesterol & 5.68 & 0.30 & $4.68^{*}$ & $0 \cdot 26$ & $4.79^{*}$ & $0 \cdot 25$ \\
\hline HDL-cholesterol & 1.39 & 0.09 & 1.33 & 0.06 & 1.40 & 0.07 \\
\hline Triglycerides & 0.88 & 0.12 & 0.98 & $0 \cdot 10$ & 1.01 & $0 \cdot 11$ \\
\hline
\end{tabular}

HDL, high-density lipoprotein.

* Values significantly different from baseline value: $P<0.005$ (paired $t$ test).

mean increases of 7,19 and $70 \%$ of the energy, carbohydrate and dietary fibre respectively over the baseline diets.

All subjects were able to consume the daily dose of pectin and tended to take it at the end of each meal. Eight of the ten subjects (five females and three males) complained of some abdominal discomfort and passing of increased flatus per rectum when consuming the pectins. Five of the eight reported this to be more of a problem with the high-methoxyl product.

\section{Serum lipid levels}

Table 3 summarizes serum lipid levels at the end of each dietary period. When all subjects were taken together, regardless of order of consumption of pectins, total cholesterol levels were significantly lower than the baseline week with both HMP and LMP. There was no significant difference in the cholesterol levels between the two types of pectin.

Fig. 1 shows the changes in cholesterol levels in greater detail, dividing the subjects into two groups and showing the weekly values. It can be seen that the reduction in total cholesterol levels occurred within the first $7 \mathrm{~d}$ of taking either pectin. When group $A$ (high-methoxyl first) changed to LMP, cholesterol levels tended to rise but fell again in the subsequent 2 weeks. No such rise occurred when group B changed from LMP to HMP. No correlation could be found between the changes in blood cholesterol and changes in fat or energy intake from week-to-week.

HDL-cholesterol levels did not change significantly over the period of study. Serum triglyceride levels were higher during the pectin periods but this was not statistically significant. This may have been related to the increased carbohydrate consumption in the 'jelly', although as the subjects' weight did not increase this is unlikely.

\section{Gastrointestinal effects}

Wet and dry weights of faeces during high- and low-methoxyl periods are shown in Table 4. Wet and dry weights were lower during the low-methoxyl period (mean differences ( \pm SE) were $36.8 \pm 18.4$ and $4.9 \pm 2.6 \mathrm{~g}$ respectively, $P<0.05$ ). Faecal water was similar in both groups.

There was no difference in mouth to anus transit times as measured by carmine between the two pectins. 

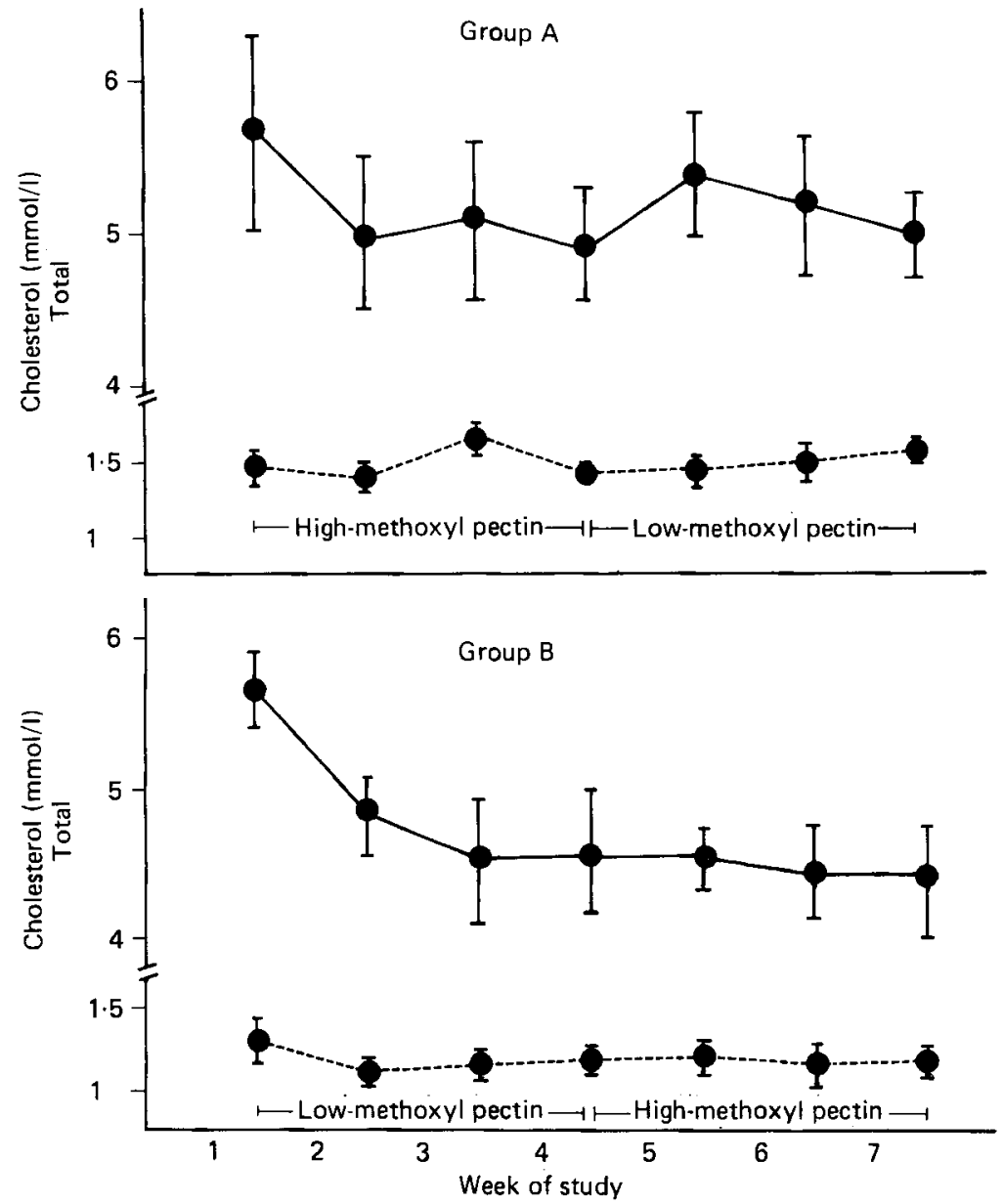

Fig. 1. Serum total ( human volunteers given low- and high-methoxyl pectins in different sequences: group $A$ and group B. Points represent means of three values at the end of each week of study.

\section{Faecal fat and steroid excretion (Table 4)}

There was no significant difference between faecal fat excretion on HMP or LMP, whether expressed as total fat excretion or fat as a percentage of intake.

A similar trend was shown by the faecal steroid excretion, i.e. excretion during HMP consumption was slightly but not significantly greater than during the low-methoxyl period. There were also no significant differences between values for coprostanol:cholesterol, or lithocholic: deoxycholic acids within the steroid fractions.

\section{DISCUSSION}

This study has demonstrated a significant reduction in serum total cholesterol levels when $15 \mathrm{~g}$ LMP (degree of methoxylation $37 \%$ ) was eaten in addition to the habitual diets of healthy young adults. The mean reduction of cholesterol was $16 \%$ and was similar to an $18 \%$ reduction found when the same subjects added $15 \mathrm{~g} \mathrm{HMP}(71 \%$ methoxylated) to their 
Table 4. Gastrointestinal effects and faecal lipid excretion in healthy adult human volunteers given low- and high-methoxyl pectin

(Mean values with their standard errors for 10 subjects)

\begin{tabular}{|c|c|c|c|c|}
\hline & \multicolumn{2}{|c|}{ High-methoxyl } & \multicolumn{2}{|c|}{ Low-methoxyl } \\
\hline & Mean & SE & Mean & SE \\
\hline Transit time $(\mathrm{h}) \dagger$ & $23 \cdot 4$ & $2 \cdot 7$ & $25 \cdot 1$ & $2 \cdot 7$ \\
\hline Faecal wt $(\mathrm{g} / \mathrm{d})$ : wet & $161^{*}$ & 21 & 124 & 8 \\
\hline Faecal wt $(\mathrm{g} / \mathrm{d})$ : dry & $39^{*}$ & $2 \cdot 5$ & 34 & 1.6 \\
\hline Faecal water $(\%)$ & $74 \cdot 1$ & $2 \cdot 1$ & $72 \cdot 5$ & $1 \cdot 4$ \\
\hline Faecal fat $(\mathrm{g} / \mathrm{d})$ & $6 \cdot 8$ & 0.8 & $6 \cdot 2$ & 0.5 \\
\hline Faecal fat $(\%$ fat intake $)$ & 6.9 & 0.9 & $6 \cdot 3$ & 0.7 \\
\hline Neutral steroids (mg/d) & 452 & 60 & 399 & 71 \\
\hline Bile acids $(\mathrm{mg} / \mathrm{d})$ & 436 & 51 & 412 & 31 \\
\hline Lithocholic: deoxycholic acid & 0.45 & 0.05 & 0.52 & 0.04 \\
\hline Coprostanol: cholesterol & 0.23 & 0.04 & $0 \cdot 19$ & 0.04 \\
\hline
\end{tabular}

* Value significantly different from that for low-methoxyl pectin, $P<0.05$ (paired $t$ test).

+ Measured as the time between consumption of carmine and its appearance in the faeces.

diets. The lower cholesterol levels were apparent after $7 \mathrm{~d}$ consumption of each pectin; suggesting similar mechanisms in operation in each case. Previous studies of the hypocholesterolaemic effect of pectin have not reported HDL-cholesterol levels, although Durrington et al. (1976) reported in their study that it was the low-density lipoprotein (LDL) fraction which was reduced. In the current experiment there were no significant changes in HDL-cholesterol levels with either pectin, thus decreasing the value for LDL (by difference): HDL compared to the control diet, a desirable effect as HDL-cholesterol is now regarded as a protective factor against ischaemic heart disease.

The cholesterol-lowering activity of pectin has previously been shown to be associated with increased excretion of total fat (Jenkins et al. 1976; Kay \& Truswell, 1977) and steroids, particularly bile acids (Lopez et al. 1968; Jenkins et al. 1976; Kay \& Truswell, 1977; Miettinen \& Tarpila, 1979), in the faeces. In the present study there were no significant differences between the two types of pectin regarding faecal lipids, though for each variable excretion was slightly higher when the HMP was consumed (in parallel with the lower serum cholesterol levels). The mechanisms by which pectin increases faecal bile acid excretion are not yet clear. Bile acids bind to various components of the dietary fibre complex (Eastwood \& Hamilton, 1968) and it has been suggested that the extent of binding may be dependent on the number of uronic acid groups rendered permanently unionized by the presence of methyl groups (Eastwood \& Mowbray, 1976). HMP would therefore be expected to be more effective as a bile acid binding agent. Animal experiments (Ershoff \& Wells, 1962; Mokady, 1973) have suggested this but we know of only one previous study in man in which pectin with a low-methoxyl content has been used, that of Delbarre et al. (1977) and here neither HMP nor LMP lowered cholesterol levels, possibly due to the low doses $(6 \mathrm{~g} / \mathrm{d})$ consumed by patients already on low-fat diets.

Other viscous polysaccharides with no methoxyl groups, such as guar gum (Jenkins et al. 1976) or psyllium seed colloid (Formon et al. 1968), have also been shown to be hypocholesterolaemic. These observations and the similarly of effect between the two pectins used in the current study add weight to the suggestion that an important factor in the hypocholesterolaemic effect may be the physical form in the small intestine. Kay \& Truswell (1977) compared the form in which pectin was administered in various studies and 
showed that the greatest reduction occurred when it was fed as a jelly with fruit and sugar (Kay \& Truswell, 1977) or with water (Jenkins et al. 1976) than when taken as capsules (Palmer \& Dixon, 1966) or in biscuits (Keys et al. 1961).

Plasma triglyceride levels were increased slightly during consumption of pectin, although not significantly.

Carbohydrate feeding is known to cause hypertriglyceridaemia and the subjects' carbohydrate intake was increased by a mean of $19 \%$ over habitual levels due to the sugar in the jelly. However, Anderson \& Chen (1979) have suggested that high intakes of complex polysaccharides prevent the hypertriglyceridaemia of carbohydrate feeding. This did not occur in the present study, although the increase in carbohydrate was small. It may be that this effect only occurs if the simple carbohydrate is intimately bound with the fibre, as in foods.

Pectins have been shown to be degraded largely by colonic bacteria (Werch \& Ivy, 1940; Cummings et al. 1979) and to have little effect on transit time or faecal weight (Kay \& Truswell, 1977; Cummings et al. 1979). In the present study transit time and faecal water were similar with both pectins but faecal wet and dry weights were higher on HMP. It has been suggested that pectins of differing methoxyl content may differ in their resistance to the alkaline medium of the small intestine and that LMP would be degraded less (Pilnik $\&$ Voragen, 1970). The dry weight values obtained in the present study do not support this concept and in the absence of analysis of fibre components in the faeces no conclusion can be drawn.

The experiment has demonstrated that LMP has similar effects on blood lipids and faecal variables to HMP when fed as a jelly to free-living volunteers. If pectin were to be used as a hypocholesterolaemic agent, a low-methoxyl type may be more useful as it is easy to incorporate into foodstuffs and has less potential for the production of methanol in the gut.

This work was partially supported by a grant from the Association of European Pectin Manufacturers. The authors would like to thank Professor A. E. Bender and Dr A. R. Leeds for help and advice, Miss R. Kloegman for technical assistance and the volunteers for their co-operation and forebearance throughout the study.

\section{REFERENCES}

American National Formulary XIII. (1970). Pectin Monograph 525.

Anderson, J. W. \& Chen, W. J. L. (1979). Am. J. clin. Nutr. 32, 346.

Carlson, K. (1973). J. clin. Path. 26, 32.

Cummings, J. H., Southgate, D. A. T., Branch, W. J., Wiggins, H. S., Houston, H., Jenkins, D. J. A., Jivraj, T. \& Hill, M. J. (1979). Br. J. Nutr. 41, 477.

Delbarre, F., Rondier, J. \& de Gery, A. (1977). Am. J. clin. Nutr. 30, 463.

Durrington, P. N., Manning, A. P., Bolton, C. H. \& Hartog, M. (1976). Lancet ji, 394.

Eastwood, M. A. \& Hamilton, D. (1968). Biochim. biophys. Acta 152, 165.

Eastwood, M. A. \& Mowbray, L. (1976). Am. J. clin. Nutr. 29, 1461.

Eggstein, M. (1966). Klin. Wschr. 44, 247.

Ershoff, B. H. \& Wells, A. F. (1962). Exp. Med. Surg. 20, 272.

Ervard, E. \& Janssen, G. (1968). J. Lipid Res. 9, 226.

Fahrenbach, M. J., Riccardi, B. A., Saunders, J. C., Lourie, N. \& Heider, J. C. (1965). Circulation 31-2, Suppl. 11.

Formon, D. T., Garvin, J. E., Forestner, J. E. \& Taylor, C. B. (1968). Proc. Soc. exp. Biol. Med. 127, 1060.

Jenkins, D. J. A., Leeds, A. R., Gassull, M. A., Houston, H., Goff, D. V. \& Hill, M. J. (1976). Clin. Sci. Mol. Med. 51, 8.

Judd, P. A., Kay, R. M. \& Truswell, A. S. (1977). Nutr. Metab. 21, 84.

Kay, R. M., Judd, P. A. \& Truswell, A. S. (1978). Am. J. clin. Nutr. 31, 562.

Kay, R. M. \& Truswell, A. S. (1977). Am. J. clin. Nutr. 30, 171. 
Kertesz, Z. I. (1963). In Comprehensive Biochemistry, p. 233 (M. Florkin and E. H. Stotz, editor). New York: Elsevier.

Keys, A., Grande, F. \& Anderson, J. T. (1961). Proc. Soc. exp. Biol. Med. 106, 555.

Lopez, A., Hopson, J. \& Krehl, W. A. (1968). Fedn. Proc., Fedn. Am. Socs. exp. Biol. $27,485$.

McKay, J. E., Stainsby, G. \& Stirrup, J. E. (1969). Private monograph. Hereford: H. P. Bulmer Ltd.

Miettinen, T. A. \& Tarpila, S. (1979). Clinica Chim. Acta 77, 471.

Mitchell, W. D., Findlay, J. M., Prescott, R. J., Eastwood, M. A. \& Horn, D. B. (1973). Gut 14, 348.

Mokady, S. (1973). Nutr. Metab. 15, 290.

Palmer, G. H. \& Dixon, D. G. (1966). Am. J. clin. Nutr. 18, 437.

Paul, A. A. \& Southgate, D. A. T. (1978). Mc Cance \& Widdowson's The Composition of Foods. London: HMSO.

Pilnik, W. \& Voragen, A. G. J. (1970). In The Biochemistry of Fruits and Their Products, p. 53 [A. C. Hulme, editor]. London: Academic Press.

Rees, D. A. (1967). The Shapes of Molecules: Carboydrate Polymers. Edinburgh: Oliver \& Boyd. Rose, G. A. (1964). Gut 5, 274.

Tan, M. H., Ulmshurst, E. G., Gleason, R. E. \& Saeldner, J. (1973). New Engl. J. Med. 289, 416.

Trinder, P. (1969). Ann. clin. Biochem. 6, 24.

Werch, S. C. \& Ivy, A. C. (1940). Proc. Soc. exp. Biol. Med. 44, 366.

Whitby, L. G. \& Lang, D. (1960). J. clin. Invest. 39, 854. 